\title{
Biology and Law
}

\author{
Richard D. Alexander
}

Museum of Zoology, Insect Division, University of Michigan

The terms "biology" and "biological" are widely used in ways that confuse and denigrate possible contributions of biologists to human self-understanding. As with social scientists, biologists deal with learning, developmental plasticity, and strategizing in virtually all species they study. It is from theories about how human strategizing is molded by selection that biologists can contribute to understanding topics like law.

\section{INTRODUCTION}

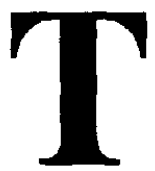

he relationship of biology and law is the central theme of this issue. In this introductory essay, I discuss some underlying questions that are both crucial and difficult. The questions involve not only the relationship of biology to law, but the more general problem of a biological approach to human behavior. They represent issues that have caused much concern and misunderstanding across the past several decades.

The first issue involves the meaning and usages of the terms "biology" and "biological." Inside the discipline of biology, these terms are used almost exclusively to refer to the science or discipline that studies life: biology is the science of life-all life. Outside biology-notably in medicine, philosophy, the social sciences, and almost all disciplines that deal explicitly with humans-biology and biological are typically used to mean "physiological" or "genetic." To take an apparently innocuous example, the "biological" father is in fact the "genetic" father. Another example, not so innocuous, is the opposing of "biological" and "cultural," or "biological" and "social." The reference is to causation: is the cause of that behavioral variation biological or cultural? Or: is it biological or social (meaning, in fact, genetic or environmental)? This usage can have pernicious effects because it is sometimes extended to the false dichotomy of whether a behavior (as opposed to a behavioral variation) is "biological or social." When this dichotomy is interpreted as "genetic or environmental" the question is, as

Received September 14-16, 1984; revised March 19, 1986.

Address reprint requests to: Dr. Richard D. Alexander, Museum of Zoology, Insect Division, University of Michigan, Ann Arbor, MI 48109. 
someone has remarked, like asking whether the area of a rectangle is owing (or owing more) to its length or to its width.

There is a certain logic behind the above dichotomies of usages when one considers the enormous 20th century expansion of the disciplines that deal with one or another aspect of human life. This expansion has caused biology to become, essentially, the discipline of all but human life. Biologists obviously do not consider most aspects of human existence in their analyses, and it is in the realms of physiology and genetics where the endeavors of biologists have typically joined those of human-oriented investigators. For a very long time, moreover, the study of behavior was all but excluded from biology as a science. Between approximately 1917 and 1950 (the period between the demise of the Journal of Animal Behavior and the appearance of Konrad Lorenz' influential paper on the study of "innate" behavior patterns), entomologists were almost the only biologists studying social behavior. There was an underlying feeling within biology that behavior could not be studied scientifically because it is too plastic, too changeable in the face of environmental fluctuations. The interesting and complex social behavior of insects could be viewed as innate or inherited, or genetically determined, and no one much cared. Parenthetically, this was a period during which some severe imprecisions in theories about how selection worked (Williams 1966) were actually responsible for the seeming intractability of behavior to scientific analysis; plasticity was erroneously given the blame.

Biology has been seen by many as (1) applying mostly to nonhuman forms of life, (2) restricted, especially in humans, to traits that tend to be directly relatable to physiological and genetic causes, and (3) explicitly not concerned with the traits that most seem to set humans apart-learning, sociality, and culture.

I believe that these dichotomies and restrictions are having negative effects on humanity's efforts at self-understanding, and that they may inject confusion into the interpretation of publications like the present issue. I also believe they are involved in the fact, that in most parts of the world, the human-oriented disciplines have become or remained significantly divorced from the development of biology as the science of life. Only in medical matters, and there only in respect to physiological and genetic phenomena, has the connection been retained. Human-oriented scientists have not been required to keep pace with even basic developments in the science of biology. In the United States, at least, it has been possible at many major universities (including my own) to obtain a Ph.D. in any aspect of the social sciences without having taken even an introductory course in the biological (or even the natural) sciences. Leaving aside detailed knowledge, a major consequence is that human-oriented scientists are not required to know about even the most broadly significant changes of focus, approach, or attitude in biology. This means that if biologists believe they have new evidence-say, from refinements of theory - that bears upon efforts of humans to understand themselves (as they now do), the very idea may be greeted 
with either groundless suspicion or misdirected enthusiasm deriving from a mixture of ignorance and the biases stemming from restricted usages of the word "biological" outside the discipline of biology.

If "biological" means "physiological," "genetic," or both, a particular approach is suggested by a "biological" approach to human social behavior. What physiological or genetic mechanisms underly behavior? How might knowledge of such mechanisms affect practical social questions such as the interpretation or practice of law? If, on the other hand, biology is defined as the science that investigates life, something considerably broader is implied, which explicitly includes the question of how plasticity has been molded by natural selection, and how the environment molds the development or expression of behavior in each individual.

One approach suggested by the narrower definition of biology is to search for a core of "basic" ("biological," "inherited," "innate," "nonmalleable," "not-so-malleable," etc.) behavior attributes. If such a core of more or less unchangeable behavior patterns could be found, one has to ask next: what might be its significance for law? Those who advocate this kind of search may say that, having located such behaviors, we may assume that we can now identify (or justify searching for) expressions of law that (1) cannot be realized because they require alteration of nonalterable behaviors or (2) ought not to be tried because they somehow stress individuals or the whole species by requiring them to do something extreme or "unnatural."

How does one recognize or locate "basic" behavioral attributes, as defined above? Some may believe it is possible by demonstrating that a behavior occurs not only in humans but in nonhuman primates related to humans. The argument seems to be that a behavior so distributed is (1) ancient, (2) has not changed, and (3) is evidently nonmalleable or must somehow be inherited. I have three reservations: (1) one must be careful to identify convergences or parallelisms (patterns that are similar or have similar functions but evolved independently) as opposed to homologies (patterns of common origin); (2) even recently appearing patterns will have some relationship to gene action, however remote and complex; and (3) an evolutionary background or a relationship to gene action in no way precludes plasticity or a strategic flexibility of response to environmental fluctuations. Quite the opposite, it is probable that every gene action must be viewed as a potential to respond or not, or to respond one way or another, depending on the particular environment (Alexander 1985b).

Another approach to locating "basic" behavioral attributes seems to lie in demonstrating particular kinds of physiological bases, mechanisms, or correlates of behavior. The implication seems to be that physiological correlates of behavior, because they are "closer" to gene effects, both prove that behavior has relatively nonmalleable aspects and also represent identification of such aspects. Finally, if a behavior found in both nonhuman primates and in humans also can be demonstrated to have particular physiological or genetic correlates, then the argument for nonmalleable or innate 
behaviors may seem to be reinforced. Caveats to all of these conclusions (hypotheses) are similar to those given above for the first.

The above mentioned approach may also be regarded, it may now be seen, as the (or "an") evolutionary approach to law: first, one focuses on behaviors which, because they are found in both nonhumans and humans, appear to have great antiquity and to have been maintained over evolutionary time, or while primates are going through long-term evolutionary changes like speciation; and second, one connects the behavior to particular physiological or genetic mechanisms, implying that it is more reasonable to view it as subject to evolution (or genetic change guided principally by natural selection). I have already suggested what could be wrong with this approach and these assumptions (Alexander, in press). Are there, however, alternative approaches that may be regarded as "evolutionary" and "biological?"

A different kind of approach, properly so labeled, does exist. This approach derives from emphasizing not the physiological or genetic (proximate) mechanisms of behavior but the adaptive or ultimate (i.e., reproductive) functions. It is generated by using, as the predictive theory, the general process of organic evolution and its (long-term) cumulative effects. Some of these effects are highly predictable because (1) there are identifiable strategies that cannot be beaten [perhaps the first example was that given by Fisher (1958) for sex ratios; for the concept of evolutionary stable strategies (ESS) see Maynard Smith and Price 1973)] and (2) variations in strategies are predictable with variations in environments (Williams 1966; Alcock 1984; Dawkins 1976, 1983; Maynard Smith 1978, 1982; Krebs and Davies 1981, 1984; Charnov 1982; Alexander 1979). I think it is fair to say that this approach is the evolutionary approach of biologists.

Evolutionary biologists generally accept that, genetically speaking, evolution is a fairly simple and singular process, evidently because life settled on DNA as the universal genetic material. Evolution is, however, guided principally by natural selection (for a review of the argument that this is so, see Alexander 1979). Selection is effected by the environment, and it is the variabilities and consistencies of patterns and sequences in environments that make the actual working of evolution a complex and challenging process to analyze.

Biologists also seem to agree-and for reasons given-that selection tends to produce individuals who in the usual environments of history behave so as to maximize the survival of their own genetic materials, as opposed to maximizing either their own survival or the survival of the group, population, or species. Precisely what is predicted from this dogma becomes a complex and intriguing science in itself (see above references, and Symons 1979; Chagnon and Irons 1979; Alexander and Tinkle 1982; and journals such as Animal Behavior, Evolution, American Naturalist, Behavioral Ecology and Sociobiology, and Ethology and Sociobiology). The reason for both the complexity and intrigue is that predictions based upon the dogma are often dramatically divergent from intuition or common sense (e.g., the sub- 
theories having to do with population regulation, sex ratios, senescence, treatment of kin, and many others-see above references for specific discussions).

An evident feature of this evolutionary approach is that it says nothing at the outset about proximate mechanisms (heredity, physiology) except that they are expected to be molded in the interests of relative success in reproduction. No claim is necessary that a distinguishable core of "basic" or unchangeable behaviors exists, or that any particular policies may place strains on human capacities or tendencies. Indeed, most of the proponents of this approach have adopted the view that for humans, as for all other organisms, lifetimes represent strategies of reproduction in the face of environments that are difficult to predict. (For example, it is clear that humans often choose "more stressful" or higher-risk courses of action when they believe that these better serve their purposes-e.g., Dickemann 1979). It is inaccurate to charge that the evolutionists' approach involves excessive determinism; on the contrary, game theory-the epitome of a rational choice theory of behavior-has been prominently incorporated into the analyses and predictions of these evolutionary biologists (e.g., Maynard Smith 1978; Krebs and Davies 1984; Dawkins 1983).

It is worth emphasizing that for social behaviors, such as those involving law, the central aspects of the environment are other strategists (other human individuals and groups). Because social strategizing is central to human life-and, arguably, is even the central theme in the evolution of humannessthe notion of a significant core of nonmalleable behaviors functioning in social life appears to be remote, and possibly even misleading or downright wrong. It would be the worst of all strategies to enter the competition and cooperativeness of social life, in which others are prepared to alter their responses, with only preprogrammed behaviors. It would be like trying to plan a game of, say, chess without reference to the moves of the other player.

Robert Axelrod, in The Evolution of Cooperation, illustrates all of the misunderstandings I have discussed. In his effort to explain the relationship between his arguments and the views that have been criticized as unwarranted extensions of genetic reductionism into the social sciences, he remarks; "this approach differs from that of sociobiology. Sociobiology is based on the assumption that important aspects of human behavior are guided by genetic inheritance (e.g., E.O. Wilson 1975). Perhaps so. But the present approach is strategic rather than genetic" (Axelrod 1984, p.ix). The dichotomy is false if "guided by genetic inheritance" is being opposed to "strategic," and also if the evolutionists' approach is being opposed to a "strategic" approach.

What, then, can evolutionary biology (or biology in general) contribute to the study of law? It can do three things. First, it can explain much that we know about ourselves but have been unable heretofore to resolve, such as the paradox of the seeming duality of selfishness and altruism in human nature that David Hume referred to over 200 years ago as the "particle of 
the dove" and the "elements of the wolf and the serpent," and that has plagued philosophers at least since ancient Greece (cf. Frankena 1980 with Alexander 1979; Trivers 1985; Chase 1980; Hirschleifer 1982; Masters 1982; Axelrod 1984).

Second, it can predict behaviors, most particularly among those still unaware of the tenets of evolutionary theory. Contrary to widespread opinion, these predictions can be detailed and nonintuitive. 1 have argued (Alexander 1978, 1979, 1982, 1985a, 1985b, in press) that predictions from biology can be useful even in arenas like the structure of law and the responses of individuals to it.'

Third, and as a result of the above two items, the approach from evolutionary biology can lead to changes in behavior that are the consequence of a deeper self-understanding of humanity. Albert Einstein is quoted as having said that the splitting of the atom ushered in an era in which humanity would be led inescapably toward disaster unless a fundamental change in its attitude toward itself and its social and political interactions could be brought about. Whether or not understanding ourselves as products of the evolutionary process can bring about the particular kind of attitude change he meant may be doubtful, but I suspect that we should be willing to take the chance.

\section{REFERENCES}

Alcock, J. Animal Behavior; An Evolutionary Approach. Sunderland, MA: Sinauer, 1984. Alexander, R.D. Natural selection and societal laws. In The Foundation of Ethics and its Relationship to Science. Vol. III. Morals, Science, and Society, T. Engelhardt and D. Callahan (Eds.). Hastings-on-Hudson, NY: Hastings Institute, 1978, pp. 138-182.

- Darwinism and Human Affairs. Seattle, WA: University of Washington Press, 1979.

- Biology and the moral paradoxes. In Law Biology, and Culture: The Evolution of Law, M. Gruter and P. Bohannan (Eds.). Santa Barbara, CA: Ross-Erikson, 1982 (Also, Journal of Social and Biological Structures 5: 389-395, 1982).

— A biological interpretation of moral systems. Zygon (1985a).

\footnotetext{
1 John H. Beckstrom, Professor of Law at Northwestern University, recently has published a book (Sociobiology and Law, Urbana and Chicago: University of Illinois Press, 1985) in which he explicitly undertakes such predictions. I appreciate his effort, which I think has been typified by intelligence and extreme thoughtfulness. As might be expected with any such pioneering effort, there are many areas of probable disagreement and controversy. The use of phrases like "the messages received by these people from their Selfish Genes" not only invites criticism but implies misunderstanding. Beckstrom's efforts at predicting people's behavior in respect to (particularly) wills show that a very great deal of knowledge and extreme cleverness is required if conscious use of evolutionary theory is to do a better job of inclusive-fitness-maximizing than is done by ordinary humans who never heard of the concept. It also indicates the inadequacies of developing single (as opposed to attempting exhaustive sets of) hypotheses and then transferring them to the status of conclusions without serious efforts at falsification. It is my view that for anyone able to keep these reservations in mind Beckstrom's book contains many useful ideas. Such predictions involve the development of a comprehensive theory of interests, which I believe (Roscoe Pound, 1941) is a necessary precursor to the analysis and understanding of all human sociality, including morality and law.
} 
Genes, consciousness, and behavior theory. In A Century of Psychology as Science, S. Koch and D. Leary (Eds.). New York: McGraw-Hill, 1985b, pp. 783-802.

The Biology of Moral Systems. Hawthorne, NY: Aldine, in press.

Tinkle, D.W. A comparative review of $O$ A Aggression and the Territorial Imperative. Bioscience 18: 245-248, 1968.

Axelrod, R. The Evolution of Cooperation. New York: Basic Books, 1984.

N. Chagnon, W. Irons (Eds.). Evolutionary Biology and Human Social Behavior: An Anthropological Perspective. North Scituate, MA: Duxbury, 1979.

Charnov, E.L. The Theory of Sex Allocation. Princeton, NJ: Princeton University Press, 1982.

Chase, I. Cooperative and noncooperative behavior in animals. American Naturalist 115: 827 $857,1980$.

Dawkins, R. The Selfish Gene. New York: Oxford, 1976.

The Extended Phenotype: The Gene as the Unit of Selection. San Francisco: W.H. Freeman, 1983.

Dickemann, M. Female infanticide, reproductive strategies, and social stratification: A primary model. In Evolutionary Biology and Human Social Behavior, N. Chagnon and W. Irons (Eds.). North Scituate, MA: Duxbury, 1979, pp. 321-367.

Fisher, R.A. The Genetical Theory of Natural Selection. New York: Dover, 1958.

Frankena, W.K. Thinking about Morality. Ann Arbor, MI: University of Michigan Press, 1980.

Hirschleifer, J. Evolutionary models in economics and law: Cooperation versus conflict strategies. Research in Law and Economics 4: 1-60, 1982.

Hume, D. Essays and Treatises on Several Subjects. Oxford: Clarendon, 1772, Vol. 2.

Krebs, J.R., Davies, N.B. An Introduction to Behavioral Ecology. Sunderland, MA: Sinauer, 1981.

—-_ Behavioral Ecology: Evolutionary Approach. Sunderland, MA: Sinauer, 1984.

Lorenz, K. The comparative method in studying innate behavior patterns. Symposium of the Society for Experimental Biology 4: 221-268, 1950.

Masters, R.D. Is sociobiology reactionary? The political implications of inclusive fitness theory. Quarterly Review of Biology 57: 275-292, 1982.

Maynard Smith, J. The Evolution of Sex. Cambridge: Cambridge University Press, 1978.

- Evolution and the Theory of Games. Cambridge: Cambridge University Press, 1982.

—_, Price, G.R. The logic of animal conflict. Nature 246: 15-18, 1973.

Pound, R. My philosophy of law. In Credos of Sixteen American Scholars. Boston, MA: Boston Law, 1941.

Symons, D. The Evolution of Human Sexuality. New York: Oxford University Press, 1979.

Trivers, R.L. Social Evolution. Menlo Park, CA: Benjamin/Cummings, 1985.

Williams, G.C. Adaptation and Natural Selection. Princeton, NJ: Princeton University Press, 1966. 